\title{
Optimal Distributed Generation Placement in Power Distribution Networks: Models, Methods, and Future Research
}

\author{
Pavlos S. Georgilakis, Senior Member, IEEE, and Nikos D. Hatziargyriou, Fellow, IEEE
}

\begin{abstract}
The integration of distributed generation (DG) units in power distribution networks has become increasingly important in recent years. The aim of the optimal DG placement (ODGP) is to provide the best locations and sizes of DGs to optimize electrical distribution network operation and planning taking into account DG capacity constraints. Several models and methods have been suggested for the solution of the ODGP problem. This paper presents an overview of the state of the art models and methods applied to the ODGP problem, analyzing and classifying current and future research trends in this field.
\end{abstract}

Index Terms-Decentralized generation, dispersed generation, distributed energy resources, distributed generation (DG), distribution systems optimization, embedded generation, optimal distributed generation placement (ODGP), planning.

\section{INTRODUCTION}

D ISTRIBUTED generation units (also called decentralized generation, dispersed generation, and embedded generation) are small generating plants connected directly to the distribution network or on the customer site of the meter. In the last decade, the penetration of renewable and nonrenewable distributed generation (DG) resources is increasing worldwide encouraged by national and international policies aiming to increase the share of renewable energy sources and highly efficient micro-combined heat and power units in order to reduce greenhouse gas emissions and alleviate global warming. Next to environmental advantages, DGs contribute in the application of competitive energy policies, diversification of energy resources, reduction of on-peak operating cost, deferral of network upgrades, lower losses and lower transmission and distribution costs, and potential increase of service quality to the end-customer. Moreover, DGs are available in modular units, characterized by ease of finding sites for smaller generators, shorter construction times, and lower capital costs.

Decision about DG placement is taken by their owners and investors, depending on site and primary fuel availability or climatic conditions. Although the installation and exploitation of

Manuscript received September 17, 2012; revised December 03, 2012; accepted December 24, 2012. Date of publication January 23, 2013; date of current version July 18, 2013. This work was supported in part by the European Commission under Contract FP7-ENERGY-2007-2-TREN-218903 (IRENE-40 Project). Paper no. TPWRS-01051-2012.

The authors are with the School of Electrical and Computer Engineering, $\mathrm{Na}-$ tional Technical University of Athens (NTUA), Athens 15780, Greece (e-mail: pgeorg@power.ece.ntua.gr; nh@power.ece.ntua.gr).

Digital Object Identifier 10.1109/TPWRS.2012.2237043
DGs to solve network problems has been debated in distribution networks, the fact is that, in most cases, the distribution system operator (DSO) has no control or influence about DG location and size below a certain limit. However, DG placement impacts critically the operation of the distribution network. Inappropriate DG placement may increase system losses and network capital and operating costs. On the contrary, optimal DG placement (ODGP) can improve network performance in terms of voltage profile, reduce flows and system losses, and improve power quality and reliability of supply. The DG placement problem has therefore attracted the interest of many research efforts in the last fifteen years [1]-[83], since it can provide DSOs, regulators, and policy makers useful input for the derivation of incentives and regulatory measures.

This paper proposes a taxonomy of ODGP models and methods, offering a unifying description of a relatively large number of works devoted to the subject. This review serves as a guide to aid researchers and power system engineers on the available DG placement models and methodologies. In comparison to [84] and [85], this paper introduces a systematic qualitative assessment of ODGP models and methods, providing the contribution of all of the reviewed ODGP works.

This paper is organized as follows. Sections II and III outline and classify the published models and methods, respectively. Section IV discusses the contribution of the reviewed works. Section V suggests future work ideas, and Section VI concludes.

\section{Mathematical Formulations}

\section{A. General Problem Statement}

The typical ODGP problem deals with the determination of the optimum locations and sizes of DG units to be installed into existing distribution networks, subject to electrical network operating constraints, DG operation constraints, and investment constraints. The ODGP is a complex mixed integer nonlinear optimization problem.

\section{B. Objective}

The objective function of the ODGP can be single or multiobjective. The main single-objective functions are: 1) minimization of the total power loss of the system;2) minimization of energy losses; 3) minimization of system average interruption duration index (SAIDI); 4) minimization of cost; 5) minimization of voltage deviations; 6) maximization of DG capacity; 7) maximization of profit; 8) maximization of a benefit/cost ratio; and 9) maximization of voltage limit loadability (i.e., the maximum 
loading that can be supplied by the power distribution system while the voltages at all nodes are kept within the limits).

ODGP multiobjective formulations can be classified as:

1) multiobjective function with weights, where the multiobjective formulation is transformed into a single objective function using the weighted sum of individual objectives;

2) goal multiobjective index, where the multiobjective formulation is transformed into a single objective function using the goal programming method;

3) multiobjective formulation considering more than one often contrasting objectives and selecting the best compromise solution in a set of feasible solutions.

\section{Number of DGs}

Depending on the number of DGs to be installed, the ODGP problem is classified as: 1) single DG or 2) multiple DGs installation.

\section{DG Variables}

The following design variables (unknowns) are alternatively computed for each DG: 1) location; 2) size; 3) location and size; 4) type, location and size; 5) number, location and size; and 6) number, type, location, and size. DG type refers to DG technology, e.g., wind, solar, biomass, fuel cell, and diesel.

As an example, let us consider the above-mentioned second case where the design variable is only the DG size. This particular class of ODGP problem is very interesting in the smart grid system, where the usage of renewable energy is expected to increase. However, placement of these renewable DGs is greatly influenced by the natural environment. Therefore, it is very important to determine the size of renewable energy when the placement is fixed [76], [81].

\section{E. Load Variables}

The load profile is modelled in ODGP as: 1) one-load level; 2) multi-load level; 3) time-varying; 4) probabilistic; and 5) fuzzy.

The load can be either distributed along the lines, or concentrated on the network buses. In case of concentrated load, the following modelling alternatives exist: 1) constant power; 2) variable power that depends on the magnitude of bus voltage; 3) probabilistic; and 4) fuzzy.

\section{F. DG Technology}

DG can be rotating devices (synchronous or asynchronous machines) directly coupled to the network, or they can be rotating or static devices interfaced via electronic converters. When connected to the power system, these DG technologies have different impacts on power system operation, control, and stability [86], [87]. For example, inverter-based DG units have voltage control capability. Moreover, they impact system harmonic levels more than synchronous-based DG. On the other hand, directly coupled rotating DG units have a much more profound effect on protection coordination than converter-interfaced DG units. Thus, these power system impacts of DG technology affect the size and optimal placement of DG [82], [83].

\section{G. Constraints}

The most common constraints in the ODGP formulation are: 1) power flow equality constraints; 2) bus voltage or voltage drop limits; and 3) line or transformer overloading or capacity limits - moreover, the following constraints have been considered in some ODGP models: 4) total harmonic voltage distortion limit; 5) short-circuit level limit; 6) reliability constraints, e.g., max SAIDI; 7) power generation limits, 8) budget limit, 9) DG with constant power factor; 10) DG penetration limit; 11) maximum number of DGs; 12) limited buses for DG installation; and 13) discrete size of DG units.

\section{H. Taxonomy}

Table I presents a taxonomy of the reviewed ODGP models.

\section{MethodS}

\section{A. Analytical Methods}

On a radial feeder with uniformly distributed load, the analytical method known as the " $2 / 3$ rule" suggests to install a DG of $2 / 3$ capacity of the incoming generation at $2 / 3$ of the length of the line [3]; however, this technique may not be effective for nonuniformly distributed loads. Two analytical methods for optimal location of a single DG with fixed size are introduced in [8]: the first method is applicable to radial and the second one to meshed power systems. An analytical method, based on the exact loss formula, is proposed to optimally site and size a single DG [20]. An analytical method using a loss sensitivity factor that is based on the equivalent current injection is developed in [38] to find the optimum size and location of a single DG. An analytical method is proposed in [39] for finding the optimal locations of multiple DGs in combination with the Kalman filter algorithm for determining their optimal size. Analytical expressions for the optimal location and size of one and two DGs are proposed in [37]. Analytical expressions for finding optimal size and power factor of different types of DGs are suggested in [49]. An analytical method described in [79] computes the optimal location and size of multiple DGs, considering also different types of DGs.

\section{B. Numerical Methods}

1) Gradient Search: Gradient search for the optimal sizing of DGs in meshed networks, ignoring and considering fault level constraints, is proposed in [1] and [17], respectively.

2) Linear Programming (LP): LP is used to solve ODGP models in [15] and [21], achieving maximum DG penetration and maximum DG energy harvesting, respectively.

3) Sequential Quadratic Programming (SQP): SQP is applied to solve ODGP without and with fault level constraints, in [53] and [10], respectively.

4) Nonlinear Programming (NLP): A discrete probabilistic generation-load model with all possible operating conditions is reduced into a deterministic model that is solved using a mixed integer nonlinear programming (MINLP) technique for optimally allocating either only wind DG units [54], or different types of DG units [44]. The ODGP is formulated as a multi-period ac optimal power flow (OPF) 
TABLE I

TAXonomy of the Reviewed Optimal DG Placement Models

\begin{tabular}{|c|c|c|c|c|c|c|}
\hline Reference & Number of DGs & Design variables & Load profile & Load model & Objective & Objective function \\
\hline$[1]$ & Multiple & Size & One load level & Constant power & Single & Min power loss \\
\hline [2] & Multiple & Size & One load level & Constant power & Single & Min power loss \\
\hline [3] & Single & Location + size & One load level & Distributed & Single & Min power loss \\
\hline [4] & Multiple & Location + size & Time varying & Distributed & Single & Min power loss \\
\hline [5] & Multiple & Location + size & Fuzzy & Fuzzy & Single & Min cost \\
\hline [6] & Multiple & Location + size & One load level & Constant power & Multiple & Multiobjective with weights \\
\hline [7] & Multiple & Location + size & Time varying & Constant power & Single & Min cost \\
\hline [8] & Single & Location & Time varying & Distributed & Single & Min power loss \\
\hline [9] & Multiple & Size & Multi-load level & Constant power & Single & Max profit \\
\hline$\lceil 10\rceil$ & Multiple & Size & One load level & Constant power & Single & Max profit \\
\hline [11] & Multiple & Location + size & Probabilistic & Constant power & Multiple & Multiobjective \\
\hline$[12]$ & Multiple & Location + size & One load level & Constant power & Single & Min cost \\
\hline$[13]$ & Multiple & Location + size & Time varying & Constant power & Single & Max DG capacity \\
\hline$[14]$ & Multiple & Location + size & One load level & Constant power & Multiple & Multiobjective \\
\hline$[15]$ & Multiple & Location + size & One load level & Constant power & Single & Max DG capacity \\
\hline$[16]$ & Multiple & Location + size & One load level & Constant power & Single & Min power loss \\
\hline$[17]$ & Multiple & Size & One load level & Constant power & Single & Max profit \\
\hline [18] & Single & Location & Time varying & Constant power & Single & Min SAIDI \\
\hline [19] & Multiple & Location + size & One load level & Constant power & Single & Max benefit/cost ratio \\
\hline$[20]$ & Single & Location + size & One load level & Constant power & Single & Min power loss \\
\hline [21] & Multiple & Location + size & Time varying & Constant power & Single & Max profit \\
\hline$[22]$ & Multiple & Number + type + location + size & One load level & Constant power & Single & Max benefit/cost ratio \\
\hline [23] & Multiple & Type + location + size & Time varying & Variable power & Multiple & Multiobjective \\
\hline [24] & Multiple & Location + size & One load level & Constant power & Single & Min cost \\
\hline [25] & Single & Location + size & One load level & Constant power & Single & Max profit \\
\hline [26] & Single & Location + size & One load level & Variable power & Single & Min power loss \\
\hline$[27]$ & Multiple & Location + size & One load level & Constant power & Single & Max profit \\
\hline$[28]$ & Multiple & Location + size & Fuzzy & Fuzzy & Multiple & Multiobjective \\
\hline [29] & Single & Location & Time varying & Constant power & Multiple & Multiobjective with weights \\
\hline$[30]$ & Multiple & Location + size & One load level & Variable power & Multiple & Multiobjective \\
\hline [31] & Multiple & Location & One load level & Constant power & Single & Min power loss \\
\hline [32] & Multiple & Location & Time varying & Constant power & Multiple & Multiobjective \\
\hline [33] & Multiple & Location + size & One load level & Variable power & Single & Min voltage deviations \\
\hline [34] & Multiple & Location & One load level & Constant power & Multiple & Multiobjective with weights \\
\hline [35] & Multiple & Location + size & One load level & Constant power & Single & Min power loss \\
\hline$[36]$ & Single & Location + size & One load level & Variable power & Multiple & Multiobjective with weights \\
\hline [37] & Multiple & Location + size & One load level & Distributed & Single & Min power loss \\
\hline [38] & Single & Location + size & One load level & Constant power & Single & Min power loss \\
\hline [39] & Multiple & Location + size & One load level & Constant power & Single & Min power loss \\
\hline$[40]$ & Multiple & Location + size & One load level & Constant power & Single & Max profit \\
\hline [41] & Multiple & Location + size & Multi-load level & Constant power & Single & Max profit \\
\hline [42] & Multiple & Size & Multi-load level & Constant power & Single & Max DG capacity \\
\hline [43] & Multiple & Size & One load level & Constant power & Single & Max DG capacity \\
\hline [44] & Multiple & Type + location + size & Time varying & Probabilistic & Single & Min energy loss \\
\hline [45] & Multiple & Number + location + size & Multi-load level & Constant power & Single & Min cost \\
\hline [46] & Multiple & Location & Time varying & Constant power & Single & Min cost \\
\hline$[47]$ & Multiple & Location + size & Time varying & Constant power & Single & Max profit \\
\hline
\end{tabular}

that is solved using NLP [42], [43], [57]. The distribution network capacity for the connection of DG is computed by an OPF formulation that is solved by an interior point method [9]. MINLP is employed for optimal allocation of different types of DG units considering electricity market price fluctuation [56]. An ODGP model in hybrid electricity market is evaluated using MINLP [45]. An integrated distribution network planning model, implementing ODGP as an alternative option, is solved by MINLP [12]. Electronically interfaced DG units, with an objective of improving the voltage stability margin, are optimally placed and sized using MINLP [82].

5) Dynamic Programming (DP): DP is applied to solve an ODGP model that maximizes the profit of the distribution network operator (DNO) and considers light, medium, and peak load conditions [58].

6) Ordinal Optimization (OO): An OO method is developed in [40] for specifying the locations and sizes of multiple DGs such that a tradeoff between loss minimization and DG capacity maximization is achieved.
7) Exhaustive Search: The ODGP is solved by an exhaustive search that seeks the DG location that optimizes the objective function (maximization of reliability or minimization of system power loss) for a given DG size [18]. An exhaustive search is proposed for solving the ODGP in distribution networks with variable power load in [26], [33], [51]. A multiobjective performance index, taking into account the time-varying behaviour of both demand and generation, when optimized by an exhaustive search, is suggested in [29].

\section{Heuristic Methods}

1) Genetic Algorithm (GA): GA and an improved Hereford ranch algorithm (variant of GA) are proposed in [2] for DGs optimal sizing. GA is applied to solve an ODGP problem with reliability constraints in [19]. GA is used to solve an ODGP that considers variable power concentrated load models [36], distributed loads [35], and constant power concentrated loads [35], [41]. A GA is employed to solve ODGP that maximizes the profit of 
TABLE I (Continued.)

TAXonomy of the ReViewed Optimal DG Placement Models

\begin{tabular}{|c|c|c|c|c|c|c|}
\hline Reference & Number of DGs & Design variables & Load profile & Load model & Objective & Objective function \\
\hline$[48]$ & Single & Location + size & One load level & Constant power & Multiple & Multiobjective with weights \\
\hline [49] & Single & Location + size & One load level & Constant power & Single & Min power loss \\
\hline$[50]$ & Single & Location + size & One load level & Constant power & Multiple & Multiobjective with weights \\
\hline [51] & Multiple & Number + location + size & One load level & Variable power & Single & Min power loss \\
\hline [52] & Multiple & Size & Multi-load level & Constant power & Single & Max DG capacity \\
\hline [53] & Multiple & Location + size & One load level & Constant power & Single & Min power loss \\
\hline [54] & Multiple & Location + size & Time varying & Probabilistic & Single & Min energy loss \\
\hline$[55]$ & Multiple & Number + type + location + size & One load level & Constant power & Single & Min power loss \\
\hline$[56]$ & Multiple & Location + size & One load level & Constant power & Multiple & Multiobjective with weights \\
\hline [57] & Multiple & Location + size & Multi-load level & Constant power & Single & Min energy loss \\
\hline [58] & Multiple & Location + size & Multi-load level & Constant power & Single & Max profit \\
\hline$[59]$ & Single & Location + size & One load level & Constant power & Single & Min power loss \\
\hline$[60]$ & Multiple & Location + size & One load level & Constant power & Multiple & Multiobjective with weights \\
\hline [61] & Multiple & Location + size & One load level & Constant power & Multiple & Multiobjective with weights \\
\hline$[62]$ & Multiple & Location + size & One load level & Constant power & Single & Max profit \\
\hline [63] & Multiple & Location + size & One load level & Variable power & Multiple & Multiobjective with weights \\
\hline$[64]$ & Single & Location + size & One load level & Variable power & Multiple & Multiobjective \\
\hline$[65]$ & Multiple & Type + location + size & Probabilistic & Probabilistic & Single & Min cost \\
\hline$[66]$ & Multiple & Location + size & One load level & Constant power & Single & Min power loss \\
\hline$[67]$ & Multiple & Type + location + size & Probabilistic & Probabilistic & Multiple & Multiobjective with weights \\
\hline [68] & Multiple & Location + size & Multi-load level & Constant power & Single & Min cost \\
\hline [69] & Single & Location & One load level & Constant power & Single & Min cost \\
\hline$[70]$ & Multiple & Location + size & One load level & Constant power & Single & Max voltage limit loadability \\
\hline$[71]$ & Multiple & Location + size & One load level & Constant power & Multiple & Multiobjective with weights \\
\hline$[72]$ & Single & Location & Multi-load level & Constant power & Single & Min power loss \\
\hline [73] & Multiple & Number + location + size & One load level & Constant power & Multiple & Goal multiobjective index \\
\hline [74] & Multiple & Location & Multi-load level & Constant power & Single & Max profit \\
\hline [75] & Multiple & Location + size & One load level & Constant power & Single & Min cost \\
\hline$[76]$ & Multiple & Size & One load level & Constant power & Single & Max DG capacity \\
\hline$[77]$ & Multiple & Location + size & Time varying & Constant power & Multiple & Multiobjective with weights \\
\hline [78] & Multiple & Location + size & One load level & Constant power & Single & Min power loss \\
\hline$[79]$ & Multiple & Location + size & One load level & Constant power & Single & Min power loss \\
\hline [80] & Multiple & Location + size & Multi-load level & Constant power & Single & Min power loss \\
\hline [81] & Multiple & Size & Time varying & Probabilistic & Single & Min cost \\
\hline$[82]$ & Multiple & Type + location + size & Time varying & Probabilistic & Single & Max voltage index \\
\hline [83] & Multiple & Type + location + size & Multi-load level & Constant power & Single & Max DG capacity \\
\hline
\end{tabular}

the DNO by the optimal placement of DGs [47]. A GA methodology is implemented to optimally allocate renewable DG units in distribution network to maximize the worth of the connection to the local distribution company as well as the customers connected to the system [81]. A value-based approach, taking into account the benefits and costs of DGs, is developed and solved by a GA that computes the optimal number, type, location, and size of DGs [22]. A GA-based method allocates simultaneously DGs and remote controllable switches in distribution networks [68]. The Chu-Beasley GA solves a nonlinear bi-level ODGP programming problem that maximizes the profits to the DG owner, subject to the minimization of payments procured by the DNO [74]. Goal programming transforms a multiobjective ODGP into a single objective ODGP, which is solved by a GA method [73]. GA and decision theory are applied to solve an ODGP problem under uncertainty including power quality issues [6]. GA and OPF are combined to solve the ODGP [27]. A fuzzy GA is used in an ODGP model that minimizes power loss cost [5]. A fuzzy GA is employed to solve a weighted multiobjective ODGP model [60], [61]. A hybrid GA and fuzzy goal programming is proposed for ODGP [30]. A combined GA and tabu search is suggested in [16]. A hybrid GA and immune algorithm solves an ODGP that maximizes the profit of the DNO [62]. GA solves a weighted multiobjective ODGP model in [48]. Multiobjective ODGP formulations are solved using a GA and an $\epsilon$-constrained method in
[11], [14], [64]. A nondominated sorting GA (NSGA) is used to maximize the distributed wind power integration [32]. NSGA-II (a variant of NSGA) in combination with a max-min approach solves a multiobjective ODGP [28]. ODGP models with uncertainties are solved by Monte Carlo simulation in conjunction with GA in [23], [67].

2) Tabu Search (TS): The ODGP problem is solved by the TS method for the case of uniformly distributed loads [4]. TS simultaneously solves ODGP and optimal placement of reactive power sources [24]. A continuous stochastic ODGP model is solved by a GA as well as by a combined TS and scatter search [65].

3) Particle Swarm Optimization (PSO): PSO is applied to solve an ODGP model in distribution system with nonunity power factor considering variable power load models [63]. An improved PSO is proposed for optimal placement of various DG types that inject real power and inject or absorb reactive power [55]. A hybrid GA and PSO is suggested in [71]. Discrete PSO computes the optimal DG location and OPF calculates the optimal DG size [75]. PSO is used for optimal selection of types, locations and sizes of both inverter-based and synchronous-based DG units to achieve maximum DG penetration considering standard harmonic limits and protection coordination constraints [83].

4) Ant Colony Optimization: An ant colony system (ACS) algorithm is proposed to solve the ODGP [34].

5) Artificial Bee Colony (ABC): An ABC method, with only two control parameters to be tuned, is proposed in [66]. 
TABLE II

Contribution of the Reviewed Optimal DG Placement Works

\begin{tabular}{|c|c|c|}
\hline Reference & Published & Contribution \\
\hline [1] & Nov. 1994 & A generalized reduced gradient method (the second order method) is proposed to compute the optimal size of DGs in selected buses. \\
\hline [2] & Oct. 1998 & A GA and an advanced Hereford ranch algorithm with improved genetic operators are introduced for ODGP. \\
\hline [3] & July 2000 & The " $2 / 3$ rule" is proposed for determining the DG location and size on a radial feeder with uniformly distributed load. \\
\hline [4] & Jan. 2001 & The TS method solves the ODGP problem for the case of uniformly distributed loads with unity power factor. \\
\hline [5] & July 2002 & The ODGP objective function and constraints are transformed into multiobjective functions with fuzzy sets solved by a fuzzy GA. \\
\hline [6] & Nov. 2003 & An ODGP model, considering power quality and DGs uncertainties, is developed and solved using GA and decision theory. \\
\hline [7] & Aug. 2004 & A market-based ODGP model is formulated and solved using a heuristic cost-benefit analysis approach. \\
\hline [8] & Nov. 2004 & Analytical methods are proposed for optimal location of a single DG in radial as well as in meshed power systems. \\
\hline [9] & Jan. 2005 & An OPF based technique has been developed that maximizes the DG capacity and identifies the available DG headroom. \\
\hline [10] & May 2005 & ODGP model that takes into account both network constraints and restrictions imposed by switchgear fault ratings. \\
\hline [11] & May 2005 & A multiobjective ODGP formulation is proposed and solved based on a GA and an $\varepsilon$-constrained method. \\
\hline [12] & May 2005 & An ODGP model is incorporated as an alternative option within an integrated distribution network-planning model. \\
\hline [13] & June 2005 & Coordinated and optimal placement of distributed generation units and reclosers into a security constrained distribution system. \\
\hline [14] & July 2005 & Multiobjective ODGP (optimization of power quality indicators and minimization of network costs) by a double trade-off method. \\
\hline [15] & Aug. 2005 & The ODGP is solved using linear programming and exploiting the interdependence of the buses with regard to the constraints. \\
\hline [16] & Aug. 2005 & The ODGP is solved by a hybrid GA and TS, where the TS helps avoid the local minimum and premature convergence of the GA. \\
\hline [17] & Nov. 2005 & Constraints imposed by fault levels are converted to simple nonlinear inequality constraints, described by the usual OPF variables. \\
\hline [18] & Feb. 2006 & Two criteria for ODGP are investigated: maximization of reliability and minimization of system power loss. \\
\hline [19] & July 2006 & An ODGP model with reliability constraints is introduced and solved using a genetic algorithm. \\
\hline$[20]$ & Dec. 2006 & An analytical method is proposed to calculate the optimal size and location of a single DG in order to minimize system power loss. \\
\hline [21] & Feb. 2007 & ODGP model that maximizes the amount of energy that may be reaped from a given area, considering its available energy resources. \\
\hline [22] & Mar. 2007 & A genetic algorithm computes the optimal number, type, location, and size of DGs in distribution feeders. \\
\hline [23] & Mar. 2007 & ODGP model for integration of stochastic generators based on accuracy improving Monte Carlo simulations nested in a GA. \\
\hline [24] & May 2007 & Optimal locations and sizes of distributed generation units and reactive power sources are computed simultaneously. \\
\hline$[25]$ & Oct. 2007 & DG placement is identified based on two rankings: locational marginal price based ranking and consumer payment based ranking. \\
\hline [26] & Nov. 2007 & The use of the variable power instead of the simplified constant power load model significantly affects the ODGP. \\
\hline [27] & Mar. 2008 & A hybrid genetic algorithm and optimal power flow technique is applied to efficiently site and size a predefined number of DGs. \\
\hline [28] & Mar. 2008 & An ODGP, which considers uncertainties using fuzzy numbers, is solved by a hybrid NSGA-II and max-min methodology. \\
\hline [29] & Apr. 2008 & The time-varying behaviour of both demand and generation are considered to accurately estimate the benefits of DG insertion. \\
\hline [30] & Apr. 2008 & Genetic algorithm in combination with fuzzy goal programming determine the optimal locations and sizes of DGs. \\
\hline [31] & July 2008 & An ODGP method based on the continuation power flow and the determination of the most sensitive buses to voltage collapse. \\
\hline [32] & Sep. 2008 & A multiobjective programming approach based on the NSGA is applied in order to maximize the integration of wind power. \\
\hline [33] & Sep. 2008 & ODGP considering the changes in the loading conditions due to contingencies on unbalanced distribution systems. \\
\hline [34] & Nov. 2008 & ACS algorithm is proposed to optimize the DG placement for a fixed recloser allocation and vice versa. \\
\hline [35] & Jan. 2009 & GA solution to ODGP problem in radial systems with distributed loads as well as in meshed systems with constant power loads. \\
\hline [36] & Feb. 2009 & Variable power concentrated loads are incorporated into an ODGP model, which is solved by a genetic algorithm. \\
\hline [37] & Apr. 2009 & Analytical expressions for the optimal location and size of microgenerators on low voltage networks with distributed loads. \\
\hline [38] & June 2009 & A loss sensitivity factor, based on the equivalent current injection, is employed for the solution of the ODGP in radial systems. \\
\hline [39] & Aug. 2009 & A hybrid analytical method combined with the Kalman filter algorithm is proposed for solving the ODGP. \\
\hline [40] & Aug. 2009 & Specific algorithmic choices for the application of ordinal optimization for locating and sizing of multiple DGs. \\
\hline [41] & Jan. 2010 & The optimal DG locations are computed by a power loss sensitivity approach and the optimal DG sizes are obtained by GA method. \\
\hline [42] & Feb. 2010 & or varlable (renewable) Dus when active network management control strategles are in operation. \\
\hline
\end{tabular}

6) Differential Evolution (DE): The optimal DG locations are computed based on incremental bus voltage sensitivities and the optimal DG sizes are calculated by DE [78].

7) Harmony Search (HS): The optimal DG location is based on loss sensitivity factors and the optimal DG size is obtained by HS algorithm [80].

8) Practical Heuristic Algorithms: A heuristic approach places a single DG based on the ranking of the energy not supplied index or the ranking of the power losses in the network lines [72]. A heuristic cost-benefit approach for ODGP to serve peak demands optimally in a competitive electricity market is introduced in [7]. A heuristic value-based approach determines the optimum location of a single DG by minimizing the system reliability cost [69]. The DG placement in wholesale electricity market is solved by two heuristic methods that are based on a locational marginal price ranking and a consumer payment ranking [25]. A heuristic iterative search technique is developed that optimizes the weighting factor of the objective function and maximizes the potential benefit thanks to the optimal DG placement [50]. Heuristic ODGP methods based on continuation power flow are proposed in [31], [70]. The ODGP is solved by voltage sensitivity analysis and loss sensitivity analysis of power flow equations in combination with a security constrained optimization method [13]. A heuristic method calculates the regions of higher probability for location of DG plants [46]. The ODGP for small distribution networks is solved by a heuristic method in [52]. The ODGP is solved by a heuristic iterative method in two stages, in which clustering techniques and exhaustive search are exploited [77]. A sensitivity test computes the optimal location and a heuristic curve-fitted technique provides the optimal size of DG [59]. Heuristic methods for sizing wind farms based on modes of voltage instability are developed in [76].

\section{Evaluation}

Analytical methods are easy to implement and fast to execute. However, their results are only indicative, since they make simplified assumptions including the consideration of only one power system loading snapshot.

Among the available numerical methods for ODGP, the most efficient are the nonlinear programming, the sequential quadratic programming and the ordinal optimization methods. The main advantage of the exhaustive search method is that it guarantees the finding of the global optimum; however, it is not 
TABLE II (Continued.)

CONTRIBUtion OF THE REVIEWEd Optimal DG Placement Works

\begin{tabular}{|c|c|c|}
\hline Reference & Published & Contribution \\
\hline [43] & Feb. 2010 & ODGP incorporating constraints that limit the voltage step change that occurs on the sudden disconnection of one or more DGs. \\
\hline [44] & Feb. 2010 & An ODGP, considering time-varying demand and generation utilizing discrete probabilistic techniques, is solved by MINLP. \\
\hline [45] & Feb. 2010 & An ODGP model for hybrid electricity markets is developed and solved using mixed-integer nonlinear programming. \\
\hline [46] & Apr. 2010 & The regions of greater probability for location of distributed generation units are computed by a probabilistic methodology. \\
\hline [47] & July 2010 & Methodology based on nodal pricing for optimally allocating distributed generation for profit maximization. \\
\hline [48] & July 2010 & GA solves an ODGP model with four different single objectives and one multiobjective formulation with weights. \\
\hline [49] & Sep. 2010 & Analytical expressions for optimal size of single DG capable of injecting real power and injecting or consuming reactive power. \\
\hline [50] & Oct. 2010 & A multiobjective ODGP model with weighting factor is developed and the optimized value of the weighting factor is computed. \\
\hline [51] & Nov. 2010 & Solution of ODGP problem for heavily overloaded networks feeding variable power loads with non-unity power factor. \\
\hline [52] & Dec. 2010 & A heuristic ODGP method is applied for solving technical problems in an actual distribution network without changing its structure. \\
\hline [53] & Dec. 2010 & Improved SQP in combination with sensitivity indices optimally place DGs with pre-specified and unspecified power factors. \\
\hline [54] & Jan. 2011 & A probabilistic approach is proposed for optimal allocation of wind-based distributed generation in distribution systems. \\
\hline [55] & Jan. 2011 & ODGP is solved by an improved PSO with mechanisms that provide better search direction and escape from local optima. \\
\hline [56] & Jan. 2011 & Optimal allocation of different types of distributed generation units considering electricity market price fluctuation. \\
\hline [57] & Feb. 2011 & It effectively captures the time-variation of multiple renewable sites and demand as well as the effect of innovative control schemes. \\
\hline [58] & Feb. 2011 & Dynamic programming is applied to solve an ODGP that considers light, medium, and peak load conditions. \\
\hline [59] & Feb. 2011 & A heuristic curve-fitted technique in combination with a sensitivity test solves the ODGP problem in radial distribution networks. \\
\hline$[60]$ & Feb. 2011 & A high performance fuzzy GA is developed to solve an ODGP that maximizes the system loading margin and the DNO profit. \\
\hline [61] & Feb. 2011 & An ODGP with a precise DG power flow model for wind turbines as well as a multiobjective function with fuzzy weights. \\
\hline [62] & Apr. 2011 & A hybrid immune-GA method is proposed for solving an ODGP that maximizes the profit of the DNO. \\
\hline [63] & July 2011 & PSO is applied for optimal placement of multiple DG units in distribution system with variable power load models. \\
\hline [64] & Aug. 2011 & Multiobjective ODGP, considering voltage rise issue and voltage dependent loads, is solved by an interactive trade-off method. \\
\hline [65] & Aug. 2011 & A continuous stochastic ODGP model considering wind power volatility and load uncertainty utilizing the moment method. \\
\hline [66] & Oct. 2011 & An $\mathrm{ABC}$ method is proposed to compute the optimal DG unit's location, size, and power factor. \\
\hline [67] & Oct. 2011 & A Monte Carlo simulation-embedded GA solves an ODGP with uncertainties represented by probability distribution functions. \\
\hline [68] & Oct. 2011 & Simultaneous allocation of DGs and remote controllable switches considering a quantized multilevel load model. \\
\hline [69] & Oct. 2011 & The optimum location of DG is based on system reliability cost that is evaluated by a probabilistic approach. \\
\hline [70] & Nov. 2011 & An ODGP model that maximizes the voltage limit loadability is solved by a heuristic method based on continuation power flow. \\
\hline [71] & Jan. 2012 & ODGP is solved by a hybrid GA-PSO, where the GA searches the site of DG and the PSO optimizes the size of DG. \\
\hline [72] & Feb. 2012 & An ODGP method based on the ranking of non-supplied energy and a method based on the ranking of power losses in lines. \\
\hline [73] & Feb. 2012 & ODGP, with a precise DG power flow model for wind turbines, is formulated as a single objective goal programming problem. \\
\hline [74] & Mar. 2012 & ODGP is formulated as a bilevel programming problem solved by Chu-Beasley GA codified to avoid non-feasible solutions. \\
\hline [75] & Mar. 2012 & A hybrid method, which employs discrete particle swarm optimization and optimal power flow, is proposed for the ODGP problem. \\
\hline [76] & Aug. 2012 & Method to increase wind penetration level by placing new wind generation at voltage stability strong wind injection buses. \\
\hline [77] & Sep. 2012 & A two-stage iterative method exploiting information on the time-varying voltage magnitude and loss sensitivity factor at each node. \\
\hline [78] & Nov. 2012 & ODGP considering voltage stability is solved by differential evolution in conjunction with incremental bus voltage sensitivities. \\
\hline [79] & Apr. 2013 & An improved analytical method computes the optimal location and size of multiple distributed generation units. \\
\hline [80] & In press & Network reconfiguration and optimal DG placement are dealt simultaneously and solved by harmony search method. \\
\hline [81] & In press & ODGP considering the uncertainty and variability associated with the output power of renewable DG as well as load variability. \\
\hline [82] & In press & ODGP to improve voltage stability considering the probabilistic nature of both the renewable resources and the load demand. \\
\hline [83] & In press & ed and synchronous-based DGs considering standard harmonic limits and protection coordination constraints. \\
\hline
\end{tabular}

suitable for large-scale systems, which is also a disadvantage for dynamic programming method.

Heuristic methods are usually robust and provide near-optimal solutions for large, complex ODGP problems. Generally, they require high computational effort. However, this limitation is not necessarily critical in DG placement applications.

\section{CONTRIBUtion OF THE REVIEWED WORKS}

Table II describes the main contribution of the published ODGP works reviewed in this paper in a chronological order.

\section{FUTURE RESEARCH}

1) Coordinated planning. Reconfiguration, capacitors placement, and DG placement are three major methods for loss reduction in distribution networks. It is interesting to investigate network reconfiguration with simultaneous placement of DGs, capacitors, and protection devices, which are dependent on each other. Moreover, traditional planning options, i.e., the addition or expansion of substations and lines should be also simultaneously considered. Such a coordinated planning can provide maximum benefits for the network owner and/or the network users; moreover, it can evaluate the feasibility of DG investment versus other traditional planning options, assuming that investment in DG is allowed by local regulation.

2) Dynamic ODGP. Static ODGP finds the optimal locations and sizes of DGs to be installed into an existing distribution network. A dynamic ODGP is needed, if multiple years are considered and optimal DG placement along the entire planning horizon is searched.

3) Uncertainties and stochastic optimization. Several parameters of ODGP are uncertain, e.g., wind power generation, solar power generation, fuel price, future load growth, market prices, future capital costs, future availability of fuel supply system, and power of plug-in electric vehicles. Consequently, stochastic optimization, or robust programming techniques can be applied to tackle with these uncertainties.

4) Active network management (ANM). The introduction of DG in the distribution system enables active operation of the distribution system, which certainly involves communication and control. DG can be used, for example, not only to control the voltage, but also to prevent overloads. Using real-time information about the operation of the network and the nature of connected DG resources, protective relay 
settings can be dynamically changed. Moreover, deployment of ANM could reduce the total costs of integrating high penetrations of DGs. ODGP models with embedded ANM schemes can help ensure adequate power quality with high penetrations of DG.

5) Islanded operation. Intentional islanding of distribution networks in the form of microgrids increases the economic competitiveness of DG and improves the reliability of these networks. It is important to identify future storage systems that will integrate with DG in islanding operation and system optimization functions (demand control) to increase the economic competitiveness of DG. Moreover, ANM with overall distribution system controls will allow controlled islanding. New ODGP models are needed to evaluate advanced methods for intentional islanding.

6) Ancillary services. DG can provide ancillary services, including those necessary to maintain a sustained and stable grid operation, e.g., provision of active power on demand of the grid. The ability of DG to provide ancillary services has to be taken into account within the ODGP model.

7) Further improvements in methods. The optimal settings of the parameters of the heuristic optimization algorithms, e.g., PSO, GA, and ACS, are computed by trial and error. These parameters can be adaptively and automatically tuned in order to improve the efficiency of the heuristic ODGP algorithms.

\section{CONCLUSION}

This paper presents a thorough description of the state-ofthe-art models and optimization methods applied to the ODGP problem, analyzing and classifying current and future research trends in this field. The most common ODGP model has the following characteristics: 1) installation of multiple DGs; 2) the design variables are the location and size; and 3 ) the objective is the minimization of the total power loss of the system. The solution methodologies for the ODGP problem are classified into three major categories: analytical, numerical and heuristic methods. The most frequently used techniques for the solution of the ODGP problem are the genetic algorithm and various practical heuristic algorithms. Future research areas include coordinated planning, dynamic ODGP, uncertainties and stochastic optimization, active network management, and islanded operation.

\section{REFERENCES}

[1] N. S. Rau and Y.-H. Wan, "Optimum location of resources in distributed planning," IEEE Trans. Power Syst., vol. 9, no. 4, pp. 2014-2020, Nov. 1994

[2] J. O. Kim, S. W. Nam, S. K. Park, and C. Singh, "Dispersed generation planning using improved Hereford ranch algorithm," Elect. Power Syst. Res., vol. 47, no. 1, pp. 47-55, Oct. 1998.

[3] H. L. Willis, "Analytical methods and rules of thumb for modeling DG-distribution interaction," in Proc. IEEE Power Eng. Soc. Summer Meeting, Jul. 2000, pp. 1643-1644.

[4] K. Nara, Y. Hayashi, K. Ikeda, and T. Ashizawa, "Application of tabu search to optimal placement of distributed generators," in Proc. IEEE Power Eng. Soc. Winter Meeting, Jan. 2001, pp. 918-923.

[5] K.-H. Kim, Y.-J. Lee, S.-B. Rhee, S.-K. Lee, and S.-K. You, "Dispersed generator placement using fuzzy-GA in distribution systems," in Proc. IEEE Power Eng. Soc. Summer Meeting, Jul. 2002, pp. 1148-1153.
[6] G. Caprinelli, G. Celli, F. Pilo, and A. Russo, "Embedded generation planning under uncertainty including power quality issues," Euro. Trans. Electr. Power, vol. 13, no. 6, pp. 381-389, Nov. 2003.

[7] W. El-Khattam, K. Bhattacharya, Y. Hegazy, and M. M. A. Salama, "Optimal investment planning for distributed generation in a competitive electricity market," IEEE Trans. Power Syst., vol. 19, no. 3, pp. 1674-1684, Aug. 2004.

[8] C. Wang and M. H. Nehrir, "Analytical approaches for optimal placement of distributed generation sources in power systems," IEEE Trans. Power Syst., vol. 19, no. 4, pp. 2068-2076, Nov. 2004.

[9] G. Harrison and A. Wallace, "Optimal power flow evaluation of distribution network capacity for the connection of distributed generation," Proc. Inst. Electr. Eng.-Gener., Transm., Distrib., vol. 152, no. 1, pp. 115-122, Jan. 2005.

[10] P. N. Vovos, G. P. Harrison, A. R. Wallace, and J. W. Bialek, "Optimal power flow as a tool for fault level-constrained network capacity analysis," IEEE Trans. Power Syst., vol. 20, no. 2, pp. 734-741, May 2005.

[11] G. Celli, E. Ghiani, S. Mocci, and F. Pilo, "A multiobjective evolutionary algorithm for the sizing and siting of distributed generation," IEEE Trans. Power Syst., vol. 20, no. 2, pp. 750-757, May 2005.

[12] W. El-Khattam, Y. G. Hegazy, and M. M. A. Salama, "An integrated distributed generation optimization model for distribution system planning," IEEE Trans. Power Syst., vol. 20, no. 2, pp. 1158-1165, May 2005.

[13] D. H. Popovic, J. A. Greatbanks, M. Begovic, and A. Pregelj, "Placement of distributed generators and reclosers for distribution network security and reliability," Int. J. Elect. Power Energy Syst., vol. 27, no. 5, pp. 398-408, Jun. 2005.

[14] G. Caprinelli, G. Celli, S. Mocci, F. Pilo, and A. Russo, "Optimisation of embedded generation sizing and siting by using a double trade-off method," Proc. Inst. Electr. Eng.-Gener., Transm., Distrib., vol. 152, no. 4, pp. 503-513, Jul. 2005.

[15] A. Keane and M. O'Malley, "Optimal allocation of embedded generation on distribution networks," IEEE Trans. Power Syst., vol. 20, no. 3, pp. 1640-1646, Aug. 2005.

[16] M. Gandomkar, M. Vakilian, and M. Ehsan, "A genetic-based tabu search algorithm for optimal DG allocation in distribution networks," Elect. Power Compon. Syst., vol. 33, no. 12, pp. 1351-1362, Aug. 2005.

[17] P. Vovos and J. Bialek, "Direct incorporation of fault level constraints in optimal power flow as a tool for network capacity analysis," IEEE Trans. Power Syst., vol. 20, no. 4, pp. 2125-2134, Nov. 2005.

[18] D. Zhu, R. P. Broadwater, K.-S. Tam, R. Seguin, and H. Asgeirsson, "Impact of DG placement on reliability and efficiency with time-varying loads," IEEE Trans. Power Syst., vol. 21, no. 1, pp. 419-427, Feb. 2006.

[19] C. L. T. Borges and D. M. Falcão, "Optimal distributed generation allocation for reliability, losses, and voltage improvement," Int. J. Elect. Power Energy Syst., vol. 28, no. 6, pp. 413-420, Jul. 2006.

[20] N. Acharya, P. Mahat, and N. Mithulananthan, "An analytical approach for DG allocation in primary distribution network," Int. J. Elect. Power Energy Syst., vol. 28, no. 10, pp. 669-678, Dec. 2006.

[21] A. Keane and M. O'Malley, "Optimal utilization of distribution networks for energy harvesting," IEEE Trans. Power Syst., vol. 22, no. 1, pp. 467-475, Feb. 2007.

[22] J.-H. Teng, Y.-H. Liu, C.-Y. Chen, and C.-F. Chen, "Value-based distributed generator placements for service quality improvements," Int. J. Elect. Power Energy Syst., vol. 29, no. 3, pp. 268-274, Mar. 2007.

[23] E. Haesen, J. Driesen, and R. Belmans, "Robust planning methodology for integration of stochastic generators in distribution grids," IET Renew. Power Gener., vol. 1, no. 1, pp. 25-32, Mar. 2007.

[24] M. E. H. Golshan and S. A. Arefifar, "Optimal allocation of distributed generation and reactive sources considering tap positions of voltage regulators as control variables," Eur. Trans. Electr. Power, vol. 17, no. 3, pp. 219-239, May 2007.

[25] D. Gautam and N. Mithulananthan, "Optimal DG placement in deregulated electricity market,” Elect. Power Syst. Res., vol. 77, no. 12, pp. 1627-1636, Oct. 2007.

[26] D. Singh, R. K. Mirsa, and D. Singh, "Effect of load models in distributed generation planning," IEEE Trans. Power Syst., vol. 22, no. 4, pp. 2204-2212, Nov. 2007.

[27] G. P. Harrison, A. Piccolo, P. Siano, and A. R. Wallace, "Hybrid GA and OPF evaluation of network capacity for distributed generation connections," Elect. Power Syst. Res., vol. 78, no. 3, pp. 392-398, Mar. 2008.

[28] M.-R. Haghifam, H. Falaghi, and O. P. Malik, "Risk-based distributed generation placement," IET Gener. Transm. Distrib., vol. 2, no. 2, pp. 252-260, Mar. 2008. 
[29] L. F. Ochoa, A. Padilha-Feltrin, and G. P. Harrison, "Evaluating distributed time-varying generation through a multiobjective index," IEEE Trans. Power Del., vol. 23, no. 2, pp. 1132-1138, Apr. 2008.

[30] K.-H. Kim, K.-B. Song, S.-K. Joo, Y.-J. Lee, and J.-O. Kim, "Multiobjective distributed generation placement using fuzzy goal programming with genetic algorithm," Eur. Trans. Electr. Power, vol. 18, no. 3, pp. 217-230, Apr. 2008.

[31] H. Hedayati, S. A. Nabaviniaki, and A. Akbarimajd, "A method for placement of DG units in distribution networks," IEEE Trans. Power Del., vol. 23, no. 3, pp. 1620-1628, Jul. 2008.

[32] L. F. Ochoa, A. Padilha-Feltrin, and G. P. Harrison, "Time-series-based maximization of distributed wind power generation integration," IEEE Trans. Energy Convers., vol. 23, no. 3, pp. 968-974, Sep. 2008.

[33] S. Kotamarty, S. Khushalani, and N. Schulz, "Impact of distributed generation on distribution contingency analysis," Elect. Power Syst. Res., vol. 78, no. 9, pp. $1537-1545$, Sep. 2008.

[34] L. Wang and C. Singh, "Reliability-constrained optimum placement of reclosers and distributed generators in distribution networks using an ant colony system algorithm," IEEE Trans. Syst., Man, Cybern. C, Appl. Rev., vol. 38, no. 6, pp. 757-764, Nov. 2008

[35] R. K. Singh and S. K. Goswami, "Optimum siting and sizing of distributed generations in radial and networked systems," Elect. Power Compon. Syst., vol. 37, no. 2, pp. 127-145, Jan. 2009.

[36] D. Singh, D. Singh, and K.-S. Verma, "Multiobjective optimization for DG planning with load models," IEEE Trans. Power Syst., vol. 24, no. 1, pp. 427-436, Feb. 2009.

[37] P. M. Costa and M. A. Matos, "Avoided losses on LV networks as a result of microgeneration," Elect. Power Syst. Res., vol. 79, no. 4, pp. 629-634, Apr. 2009.

[38] T. Gözel and M. H. Hocaoglu, "An analytical method for the sizing and siting of distributed generators in radial systems," Elect. Power Syst. Res., vol. 79, no. 6, pp. 912-918, Jun. 2009.

[39] S.-H. Lee and J.-W. Park, "Selection of optimal location and size of multiple distributed generations by using Kalman filter algorithm," IEEE Trans. Power Syst., vol. 24, no. 3, pp. 1393-1400, Aug. 2009.

[40] R. A. Jabr and B. C. Pal, "Ordinal optimisation approach for locating and sizing of distributed generation," IET Gener., Transm., Distrib., vol. 3, no. 8, pp. 713-723, Aug. 2009.

[41] T. N. Shukla, S. P. Singh, V. Shrinivasarao, and K. B. Naik, "Optimal sizing of distributed generation placed on radial distribution systems," Elect. Power Compon. Syst., vol. 38, no. 3, pp. 260-274, Jan. 2010.

[42] L. F. Ochoa, C. J. Dent, and G. P. Harrison, "Distribution network capacity assessment: Variable DG and active networks," IEEE Trans. Power Syst., vol. 25, no. 1, pp. 87-95, Feb. 2010.

[43] C. J. Dent, L. F. Ochoa, and G. P. Harrison, "Network distributed generation capacity analysis using OPF with voltage step constraints," IEEE Trans. Power Syst., vol. 25, no. 1, pp. 296-304, Feb. 2010.

[44] Y. M. Atwa, E. F. El-Saadany, M. M. A. Salama, and R. Seethapathy, "Optimal renewable resources mix for distribution system energy loss minimization," IEEE Trans. Power Syst., vol. 25, no. 1, pp. 360-370, Feb. 2010

[45] A. Kumar and W. Gao, "Optimal distributed generation location using mixed integer non-linear programming in hybrid electricity markets," IET Gener. Transm. Distrib., vol. 4, no. 2, pp. 281-298, Feb. 2010.

[46] H. M. Khodr, M. R. Silva, Z. Vale, and C. Ramos, "A probabilistic methodology for distributed generation location in isolated electrical service area," Electr. Power Syst. Res., vol. 80, no. 4, pp. 390-399, Apr. 2010.

[47] R. K. Singh and S. K. Goswami, "Optimum allocation of distributed generations based on nodal pricing for profit, loss reduction, and voltage improvement including voltage rise issue," Int. J. Electr. Power Energy Syst., vol. 32, no. 6, pp. 637-644, Jul. 2010.

[48] A. A. A. El-Ela, S. M. Allam, and M. M. Shatla, "Maximal optimal benefits of distributed generation using genetic algorithms," Electr. Power Syst. Res., vol. 80, no. 7, pp. 869-877, Jul. 2010.

[49] D. Q. Hung, N. Mithulananthan, and R. C. Bansal, "Analytical expressions for DG allocation in primary distribution networks," IEEE Trans. Energy Convers., vol. 25, no. 3, pp. 814-820, Sep. 2010.

[50] S. Ghosh, S. P. Ghoshal, and S. Ghosh, "Optimal sizing and placement of distributed generation in a network system," Int. J. Electr. Power Energy Syst., vol. 32, no. 8, pp. 849-856, Oct. 2010.

[51] H. Khan and M. A. Choudhry, "Implementation of distributed generation (IDG) algorithm for performance enhancement of distribution feeder under extreme load growth," Int. J. Electr. Power Energy Syst., vol. 32, no. 9, pp. 985-997, Nov. 2010.
[52] G. N. Koutroumpezis and A. S. Safigianni, "Optimum allocation of the maximum possible distributed generation penetration in a distribution network," Electr. Power Syst. Res., vol. 80, no. 12, pp. 1421-1427, Dec. 2010.

[53] M. F. AlHajri, M. R. AlRashidi, and M. E. El-Hawary, "Improved sequential quadratic programming approach for optimal distribution generation deployments via stability and sensitivity analyses," Electr. Power Compon. Syst., vol. 38, no. 14, pp. 1595-1614, Dec. 2010.

[54] Y. M. Atwa and E. F. El-Saadany, "Probabilistic approach for optimal allocation of wind-based distributed generation in distribution systems," IET Renew. Power Gener., vol. 5, no. 1, pp. 79-88, Jan. 2011.

[55] W. Prommee and W. Ongsakul, "Optimal multiple distributed generation placement in microgrid system by improved reinitialized social structures particle swarm optimization," Euro. Trans. Electr. Power, vol. 21, no. 1, pp. 489-504, Jan. 2011.

[56] S. Porkar, P. Poure, A. Abbaspour-Tehrani-Fard, and S. Saadate, "Optimal allocation of distributed generation using a two-stage multi-objective mixed-integer-nonlinear programming," Eur. Trans. Electr. Power, vol. 21, no. 1, pp. 1072-1087, Jan. 2011.

[57] L. F. Ochoa and G. P. Harrison, "Minimizing energy losses: Optimal accommodation and smart operation of renewable distributed generation," IEEE Trans. Power Syst., vol. 26, no. 1, pp. 198-205, Feb. 2011.

[58] N. Khalesi, N. Rezaei, and M.-R. Haghifam, "DG allocation with application of dynamic programming for loss reduction and reliability improvement," Int. J. Electr. Power Energy Syst., vol. 33, no. 2, pp. 288-295, Feb. 2011

[59] F. S. Abu-Mouti and M. E. El-Hawary, "Heuristic curve-fitted technique for distributed generation optimisation in radial distribution feeder systems," IET Gener., Transm., Distrib., vol. 5, no. 2, pp. 172-180, Feb. 2011.

[60] M. F. Akorede, H. Hizam, I. Aris, and M. Z. A. Ab Kadir, "Effective method for optimal allocation of distributed generation units in meshed electric power systems," IET Gener., Transm., Distrib., vol. 5, no. 2, pp. 276-287, Feb. 2011.

[61] K. Vinothkumar and M. P. Selvan, "Fuzzy embedded genetic algorithm method for distributed generation planning," Electr. Power Compon. Syst., vol. 39, no. 4, pp. 346-366, Feb. 2011.

[62] A. Soroudi and M. Ehsan, "Efficient immune-GA method for DNOs in sizing and placement of distributed generation units," Eur. Trans. Electr. Power, vol. 21, no. 3, pp. 1361-1375, Apr. 2011.

[63] A. M. El-Zonkoly, "Optimal placement of multi-distributed generation units including different load models using particle swarm optimisation," IET Gener., Transm., Distrib., vol. 5, no. 7, pp. 760-771, Jul. 2011.

[64] R. K. Singh and S. K. Goswami, "Multi-objective optimization of distributed generation planning using impact indices and trade-off technique," Elect. Power Compon. Syst., vol. 39, no. 11, pp. 1175-1190, Aug. 2011.

[65] C. Novoa and T. Jin, "Reliability centered planning for distributed generation considering wind power volatility," Elect. Power Syst. Res., vol. 81, no. 8, pp. 1654-1661, Aug. 2011.

[66] F. S. Abu-Mouti and M. E. El-Hawary, "Optimal distributed generation allocation and sizing in distribution systems via artificial bee colony algorithm," IEEE Trans. Power Del., vol. 26, no. 4, pp. 2090-2101, Oct. 2011.

[67] Z. Liu, F. Wen, and G. Ledwich, "Optimal siting and sizing of distributed generators in distribution systems considering uncertainties," IEEE Trans. Power Del., vol. 26, no. 4, pp. 2541-2551, Oct. 2011.

[68] M. Raoofat, "Simultaneous allocation of DGs and remote controllable switches in distribution networks considering multilevel load model," Int. J. Electr. Power Energy Syst., vol. 33, no. 8, pp. 1429-1436, Oct. 2011.

[69] B. Banerjee and S. M. Islam, "Reliability based optimum location of distributed generation," Int. J. Electr. Power Energy Syst., vol. 33, no. 8, pp. 1470-1478, Oct. 2011.

[70] N. G. A. Hemdan and M. Kurrat, "Efficient integration of distributed generation for meeting the increased load demand," Int. J. Electr. Power Energy Syst., vol. 33, no. 9, pp. 1572-1583, Nov. 2011.

[71] M. H. Moradi and M. Abedini, "A combination of genetic algorithm and particle swarm optimization for optimal DG location and sizing in distribution systems," Int. J. Electr. Power Energy Syst., vol. 34, no. 1, pp. 66-74, Jan. 2012.

[72] H. Hamedi and M. Gandomkar, "A straightforward approach to minimizing unsupplied energy and power loss through DG placement and evaluating power quality in relation to load variations over time," Int. J. Electr. Power Energy Syst., vol. 35, no. 1, pp. 93-96, Feb. 2012. 
[73] K. Vinothkumar and M. P. Selvan, "Distributed generation planning: A new approach based on goal programming," Electr. Power Compon. Syst., vol. 40, no. 5, pp. 497-512, Feb. 2012.

[74] J. M. López-Lezama, J. Contreras, and A. Padilha-Feltrin, "Location and contract pricing of distributed generation using a genetic algorithm," Int. J. Electr. Power Energy Syst., vol. 36, no. 1, pp. 117-126, Mar. 2012.

[75] M. Gomez-Gonzalez, A. López, and F. Jurado, "Optimization of distributed generation systems using a new discrete PSO and OPF," Elect. Power Syst. Res., vol. 84, no. 1, pp. 174-180, Mar. 2012.

[76] A. A. Tamimi, A. Pahwa, and S. Starrett, "Effective wind farm sizing method for weak power systems using critical modes of voltage instability," IEEE Trans. Power Syst., vol. 27, no. 3, pp. 1610-1617, Aug. 2012.

[77] F. Rotaru, G. Chicco, G. Grigoras, and G. Cartina, "Two-stage distributed generation optimal sizing with clustering-based node selection," Int. J. Electr. Power Energy Syst., vol. 40, no. 1, pp. 120-129, Sep. 2012.

[78] L. D. Arya, A. Koshti, and S. C. Choube, "Distributed generation planning using differential evolution accounting voltage stability consideration," Int. J. Electr. Power Energy Syst., vol. 42, no. 1, pp. 196-207, Nov. 2012.

[79] D. Q. Hung and N. Mithulananthan, "Multiple distributed generators placement in primary distribution networks for loss reduction," IEEE Trans. Ind. Electron., vol. 60, no. 4, pp. 1700-1708, Apr. 2013.

[80] R. S. Rao, K. Ravindra, K. Satish, and S. V. L. Narasimham, "Power loss minimization in distribution system using network reconfiguration in the presence of distributed generation," IEEE Trans. Power Syst., to be published.

[81] M. F. Shaaban, Y. M. Atwa, and E. F. El-Saadany, "DG allocation for benefit maximization in distribution networks," IEEE Trans. Power Syst., to be published.

[82] R. S. Al Abri, E. F. El-Saadany, and Y. M. Atwa, "Optimal placement and sizing method to improve the voltage stability margin in a distribution system using distributed generation," IEEE Trans. Power Syst., to be published.

[83] V. R. Pandi, H. H. Zeineldin, and W. Xiao, "Determining optimal location and size of distributed generation resources considering harmonic and protection coordination limits," IEEE Trans. Power Syst., to be published.

[84] A. Keane, L. F. Ochoa, C. L. T. Borges, G. W. Ault, A. D. Alarcon-Rodriguez, R. A. F. Currie, F. Pilo, C. Dent, and G. P. Harrison, "State-ofthe-art techniques and challenges ahead for distributed generation planning and optimization," IEEE Trans. Power Syst., to be published.
[85] A. Alarcon-Rodriguez, G. Ault, and S. Galloway, "Multi-objective planning of distributed energy resources: A review of the state-of-the-art," Renew. Sustain. Energy Rev., vol. 14, no. 5, pp. 1353-1366, Jun. 2010.

[86] R. A. Walling, R. Saint, R. C. Dugan, J. Burke, and L. A. Kojovic, "Summary of distributed resources impact on power delivery systems," IEEE Trans. Power Del., vol. 23, no. 3, pp. 1636-1644, Jul. 2008.

[87] T. Ackermann and V. Knyazkin, "Interaction between distributed generation and the distribution network: Operation aspects," in Proc. IEEE T\&D Conf., 2002, pp. 1357-1362.

Pavlos S. Georgilakis (M'01-SM'11) received the Diploma and Ph.D. degrees in electrical and computer engineering from the National Technical University of Athens, Athens, Greece, in 1990 and 2000, respectively.

$\mathrm{He}$ is currently a Lecturer at the School of Electrical and Computer Engineering, National Technical University of Athens, Athens, Greece. From 2004 to 2009, he was an Assistant Professor with the Production Engineering and Management Department, Technical University of Crete, Chania, Greece. His current research interests include power systems optimization, renewable energy sources and distributed generation.

Nikos D. Hatziargyriou (SM'90-F'09) received the Diploma degree in electrical and mechanical engineering from the National Technical University of Athens, Athens, Greece, in 1976, and the M.Sc. and Ph.D. degrees from the University of Manchester Institute of Science and Technology, Manchester, U.K., in 1979 and 1982, respectively.

He is currently Professor with the School of Electrical and Computer Engineering, National Technical University of Athens, Athens, Greece. From February 2007 to September 2012, he was Deputy CEO of the Public Power Corporation, the Electricity Utility of Greece, responsible for transmission and distribution networks. His research interests include dispersed and renewable generation, dynamic security assessment, and application of artificial intelligence techniques to power systems.

Prof. Hatziargyriou is a convener of CIGRE Study Committee C6 "Dispersed Generation" and member of the Technical Chamber of Greece. 